\title{
Effect of Host Plants on the Growth and Development of the Polyphagous Defoliator Cricula Trifenestrata Helfer (Lepidoptera: Saturniidae)
}

\author{
S. K. Gharde ${ }^{1}$ and N. Chaudhuri ${ }^{*}$
}

${ }^{1}$ Dept. of Agricultural Entomology, ${ }^{2}$ Dept. of Agricultural Entomology, RRS, Terai Zone, Uttar Banga Krishi Viswavidyalaya, Pundibari, Cooch Behar (736 165), West Bengal, India

Corresponding Author

N. Chaudhuri

e-mail:nc_ubkv@rediffmail.com

\author{
Article History \\ Article ID: AR1761 \\ Received in $30^{\text {th }}$ Dec, 2016 \\ Received in revised form $26^{\text {th }}$ July, 2017 \\ Accepted in $3^{\text {rd }}$ August, 2017
}

\begin{abstract}
The effect of four host plant species [Mango, Mangifera indica L., Cinnamon, Cinnamomum cassia, Cashew, Anacardium occidentale L., Som, Machilus bombycina King], on biology of the polyphagous defoliator Cricula trifenestrata Helfer (Lepidoptera: Saturniidae) was studied. $C$ trifenestrata completed four generations in a year. The generation time changed according to temperature and relative humidity. Biological parameters of the caterpillar differed significantly among the host plants and in different generations completed in a year. The larval developmental period was longest 42.17-43.81 days in January-March generation. The overall developmental duration was shortest in March-May generation and longest in May-October generation. The generation time was shorter on M. bombycina (85.57-145.12 days and 86.35-149.56 days for males and females, respectively) and $M$. indica (84.97-143.63 days and 87.27-148.55 days for males and females, respectively), whereas it was longest on C. cassia (88.56-147.93 days and 90.28-153.21 days for males and females, respectively). The adult longevity was longest (3.23-4.15 days) in the October-January generation. The total number of eggs per female for all the generations varied between 62.34 and 122.30 and it was highest on $M$. bombycina and $M$. indica in October-January generation. Degree days per generation changed between 943.74 DD and 1971.08 DD. Biological properties of the pest changed in each generation. In this study, the biological parameters of $C$. trifenestrata were determined for different host plants in different generations and this data can be used as an important step towards developing successful Integrated Pest Management strategies.
\end{abstract}

Keywords: Degree day, generations, host plants, incubation, Cricula trifenestrata

\section{Introduction}

Cricula trifenestrata Helfer (Saturniidae: Lepidoptera) is regarded as an important defoliator and the habitat ranges from the low land to highland at an altitude of over $2000 \mathrm{~m}$ in Meghalaya, Assam, Tripura and West Bengal (Tikader et al., 2014). The larvae live in large groups (Lampe, 2010) and often eat the whole leaf lamina, leaving only the midrib, and in the worst cases completely defoliate the Mango trees (Ghosh, 1940; Ali and Karim, 1991). In a severe case, the caterpillars devour the entire leaf blade except the midrib giving a broom like appearance in Som plant, the food plant of muga silkworm (Ahmed et al., 2012). The last larval stage is the most destructive, that consumed over $60 \%$ of leaves (Chaudhuri and Ghosh, 2012) in terai region of West Bengal. In recent years it was observed to cause serious damage to the different host plants and become one of the major pests of Mango and Som. This insect multiplies four times in a year and lives on mango and several other as well as wild plants (Hossain, 1989). Understanding insect-host plant interactions and their impact on development and various fitness parameters of an insect pest is a central theme in ecology (Miller et al. 1986; Benrays and Chapman, 1994). To understand the host suitability of plant infesting insect species, the study of the effect of host plants on the biology of insects is very important (Khaliq et al., 2014). Reports suggested that it is one of the most important destructive insect pests of Mango (Ali and Karim, 1991; Bera, 2013), hence widely known as Mango leaf defoliator. It is a voracious feeder which infests a variety of plant species having economic importance and migrates from one place to another depending on the availability of food plants (Tikader et al., 2014). Besides Mango it has been reported to cause damage to Cashew (Mandal, 2000; Rajesh and Zachariah, 2011; Pal and Medda, 2006), Cinnamon (Ahmad and Ahmad, 1991), Cardamom (Yadav and Kumar, 2003), Som (the food plant of muga silkworm) (Tikader, 2011, Ahmed et al., 2012), Litchi, Ber and Pepper (Nair, 1975); Som, Mango, Ber and Bakul (Biswas et al., 2013), plantation crop (Arora and Gupta, 1979; Das et al., 1999).

An in-depth study of the $C$. trifenestrata was attempted by 
various scientists on biology was restricted to single host plant only. Cricula trifenestrata being polyphagous thrives on a wide range of host plants and cause considerable damage of different plants of economic values. The study on the biology of the polyphagous defoliator Cricula trifenestrata Helfer on different host species in different generations completed in a year was not investigated in detail. Therefore, an understanding of this relationship is needed to develop a reliable developmental model for $C$. trifenestrata in order to formulate effective pest management plans.

In view of that the present study was taken to study the growth and development of $C$. trifenestrata on four host plant species, namely Mango (Mangifera indica L., Anacardiaceae), Cashew (Anacardium occidentale L., Anacardiaceae), Cinnamon (Cinnamomum cassia, Lauraceae) and Som (Machilus bombycina K., Lauraceae) for four generations, in order to estimate parameters for population increase on the different host plants to guide pest management decisions.

\section{Materials and Methods}

\subsection{Maintenance of stock culture}

Rearing of Cricula was carried out on leaves of four different host plants namely namely Mango (Mangifera indica L., Anacardiaceae), Cashew (Anacardium occidentale L., Anacardiaceae), Cinnamon (Cinnamomum cassia, Lauraceae) and Som (Machilus bombycina K., Lauraceae). The twigs of each host plant were collected from the Instructional Farm, Uttar Banga Krishi Viswavidyalaya, Pundibari, Cooch Behar, West Bengal, India. Pupae of Cricula trifenestrata were collected from the orchard of Uttar Banga Krishi Viswavidyalaya, Pundibari, Cooch Behar and kept in well-aerated cage till adult emergence. The mated adults were collected and transferred to different cages with twigs of respective host plants for oviposition. The stock culture of $C$. trifenestrata on each of the host plant species was maintained in the Laboratory of the department of agricultural entomology Uttar Banga Krishi Viswavidyalaya, Pundibari, Cooch Behar, West Bengal, India.

\subsection{Rearing of cricula trifenestrata Helfer}

The rearing of Cricula trifenestrata Helfer was conducted during 2013 to 2015. The twig of four host plants with freshly laid eggs were kept separately in water filled conical flasks lined with cotton plug to prevent desiccation, and egg hatch was determined. Emerging larvae from each cohort of eggs were removed using a camel hair brush $(\# 000)$ and placed in a separate petridish. The tender leaves of four different host plants were provided to the newly hatched larvae. Fresh leaves were supplied to each petridish as food and the leaves were renewed at 12 -hour interval. The first and second instar were reared in petridish, third and fourth in plastic jars while fifth and sixth were reared in plastic buckets. Wet cotton was used to keep the leaves fresh. Ten (10) larvae were taken for the study and five (5) replications were maintained. The cocoon on full formation were removed and kept on paper in well-aerated cage until the emergence of adults.

\subsection{Reproduction, longevity}

Thirty (30) newly emerged adults reared on each of the host plant species were allowed to mate in 2:1 male-female sex ratio. After mating, females were transferred to the cage with respective host plants placed in a water filled conical flask for oviposition and observed daily until they died. Each of the female was counted as a replication. The total number of eggs produced by each female was recorded. Observations were recorded on incubation period, larval and pupal period and adult longevity. The overall developmental duration from egg to adult were calculated for both male and female.

The developmental times of each life stage of $C$. trifenestrata were analyzed using the PROC GLM in SAS (SAS version, 9.2). The statistical differences of developmental duration among the host and generation were evaluated by two-way analysis of variance. Significant differences among multiple means were determined by using Tukey's studentized range test.

2.4. Determination of thermal constant and development threshold of different developmental stages

Weekly data of abiotic factors such as maximum temperature, minimum temperature, were recorded properly from the Agro-Meteorological Centre of the University.

Development rate for egg, larva and pupal stage was calculated as reciprocal of their respective developmental duration (D) such that $R=1 / D$.

Development threshold (To) and thermal constant (K) were then determined by regressing development rate on temperature (Kipyatov and Lopatina, 2010).

The To was determined as ratio of regression intercept (a) and $b ; T_{0}=-a / b$

The $K$ was estimated as reciprocal of regression coefficient (b) between development rate and temperature; $K=1 / b$

Data thus collected in two years of study were pooled and analyzed statistically using statistical software EXCEL and SAS (Ver. 9.2). The analysis was made among the host plants in each generation.

\section{Results and Discussion}

The insect completes four (4) generations in a year in terai region of West Bengal. The overall developmental duration from egg to adult as well as that of the various developmental stages of $C$. trifenestrata and the fecundity varied significantly across the host plants and different generations completed in a year (Table 1 and 2 ).

\subsection{Incubation period}

The shortest incubation period (Table 1 and 2) was observed in the March-May (9.88-10.10 days) generation while the longest was in the January-March (14.40-14.65 days) generation. In different host plants eggs took comparably longer period to hatch on $M$. indica.

\subsection{Larval period}

The development of the first instar larvae ranged from 


\begin{tabular}{|c|c|c|c|c|c|c|c|c|c|}
\hline \multirow{2}{*}{\multicolumn{2}{|c|}{$\begin{array}{l}\text { Generations } \\
\text { Mean temperature (min-max) }\end{array}$}} & \multicolumn{4}{|c|}{ January-March } & \multicolumn{4}{|c|}{ March-May } \\
\hline & & \multicolumn{4}{|c|}{$20.13^{\circ} \mathrm{C}\left(13.26-27.00^{\circ} \mathrm{C}\right)$} & \multicolumn{4}{|c|}{$25.87^{\circ} \mathrm{C}\left(20.08-30.49^{\circ} \mathrm{C}\right)$} \\
\hline \multicolumn{2}{|c|}{ Mean RH (min-max) } & & $9 \%(48.25$ & $-82.61 \%$ & & & $50 \%(59$. & $6-85.66 \%$ & \\
\hline \multicolumn{2}{|l|}{ Host Plants } & $\mathrm{M}$ & $\mathrm{Cn}$ & $\mathrm{Ca}$ & $\mathrm{S}$ & $\mathrm{M}$ & $\mathrm{Cn}$ & $\mathrm{Ca}$ & $\mathrm{S}$ \\
\hline \multicolumn{10}{|c|}{ Biological parameters } \\
\hline \multicolumn{2}{|l|}{ Egg } & 14.65 & 14.50 & 14.40 & 14.45 & 9.90 & 9.88 & 9.90 & 10.10 \\
\hline \multirow[t]{6}{*}{ Larva } & $1^{\text {st }}$ & 8.68 & 8.13 & 8.06 & 8.85 & 8.39 & 8.33 & 8.06 & 8.40 \\
\hline & $2^{\text {nd }}$ & 6.10 & 5.95 & 5.95 & 6.13 & 4.93 & 4.98 & 4.83 & 4.83 \\
\hline & $3^{\text {rd }}$ & 7.18 & 7.00 & 7.08 & 7.15 & 6.02 & 5.81 & 5.80 & 5.87 \\
\hline & $4^{\text {th }}$ & 6.38 & 6.23 & 6.60 & 6.58 & 5.48 & 6.30 & 5.95 & 6.24 \\
\hline & $5^{\text {th }}$ & 7.31 & 7.90 & 6.84 & 6.91 & 7.78 & 7.95 & 6.90 & 7.30 \\
\hline & $6^{\text {th }}$ & 8.20 & 9.63 & 8.29 & 8.13 & 10.00 & 10.50 & 8.80 & 9.20 \\
\hline \multirow[t]{2}{*}{ Pupa } & Male & 22.00 & 23.00 & 22.90 & 22.40 & 26.20 & 28.00 & 27.00 & 25.30 \\
\hline & Female & 22.80 & 24.20 & 24.40 & 23.45 & 27.10 & 28.80 & 27.60 & 26.70 \\
\hline \multirow[t]{2}{*}{ Adult longevity } & Male & 3.43 & 3.18 & 2.79 & 3.36 & 3.14 & 3.41 & 3.18 & 3.17 \\
\hline & Female & 3.55 & 3.73 & 3.90 & 3.63 & 3.84 & 3.87 & 3.85 & 3.86 \\
\hline \multirow[t]{2}{*}{ Total development } & Male & 87.35 & 88.69 & 85.69 & 87.31 & 84.97 & 88.56 & 83.64 & 83.57 \\
\hline & Female & 88.39 & 90.99 & 89.41 & 88.90 & 87.27 & 90.28 & 85.58 & 86.35 \\
\hline \multicolumn{2}{|l|}{ Fecundity } & 78.26 & 73.69 & 74.06 & 78.96 & 71.00 & 64.00 & 67.10 & 71.83 \\
\hline \multicolumn{10}{|l|}{ Table 1: Continue... } \\
\hline \multicolumn{2}{|l|}{ Generations } & \multicolumn{4}{|c|}{ May-October } & \multicolumn{4}{|c|}{ October-January } \\
\hline \multicolumn{2}{|c|}{ Mean temperature (min-max) } & \multicolumn{4}{|c|}{$27.98^{\circ} \mathrm{C}\left(23.89-32.28^{\circ} \mathrm{C}\right)$} & \multicolumn{4}{|c|}{$20.99^{\circ} \mathrm{C}\left(15.13-27.27^{\circ} \mathrm{C}\right)$} \\
\hline \multicolumn{2}{|c|}{ Mean RH (min-max) } & \multicolumn{4}{|c|}{$83.97 \%(74.82-92.60 \%)$} & \multicolumn{4}{|c|}{$79.13 \%(69.94-88.34 \%)$} \\
\hline Host Plants & & $\mathrm{M}$ & $\mathrm{Cn}$ & $\mathrm{Ca}$ & $\mathrm{s}$ & $\mathrm{M}$ & $\mathrm{Cn}$ & $\mathrm{Ca}$ & $\mathrm{s}$ \\
\hline \multicolumn{10}{|c|}{ Biological parameters } \\
\hline Egg & & 10.40 & 10.50 & 10.50 & 10.35 & 10.23 & 10.09 & 10.00 & 10.05 \\
\hline Larva & $1^{\text {st }}$ & 6.25 & 6.66 & 6.55 & 6.70 & 7.74 & 7.48 & 7.38 & 7.60 \\
\hline & $2^{\text {nd }}$ & 5.75 & 5.94 & 5.83 & 5.82 & 5.55 & 5.45 & 5.35 & 5.43 \\
\hline & $3^{\text {rd }}$ & 6.18 & 6.23 & 6.25 & 6.16 & 5.20 & 5.45 & 5.20 & 5.23 \\
\hline & $4^{\text {th }}$ & 5.96 & 6.05 & 5.83 & 6.20 & 5.84 & 6.34 & 5.88 & 6.05 \\
\hline & $5^{\text {th }}$ & 6.26 & 6.83 & 6.35 & 6.17 & 6.25 & 6.55 & 6.23 & 6.45 \\
\hline & $6^{\text {th }}$ & 8.58 & 8.85 & 8.38 & 8.63 & 9.41 & 9.99 & 9.50 & 9.30 \\
\hline Pupa & Male & 88.20 & 90.80 & 89.60 & 89.10 & 56.00 & 56.70 & 56.00 & 55.10 \\
\hline & Female & 92.20 & 95.30 & 93.80 & 92.80 & 60.00 & 60.90 & 60.60 & 59.40 \\
\hline Adult longevity & Male & 3.03 & 3.04 & 2.95 & 3.00 & 3.38 & 3.51 & 3.23 & 3.43 \\
\hline & Female & 3.49 & 3.43 & 3.45 & 3.37 & 4.00 & 4.01 & 4.15 & 4.12 \\
\hline Total development & Male & 143.63 & 147.93 & 145.18 & 145.12 & 112.98 & 115.07 & 111.99 & 112.06 \\
\hline & Female & 148.55 & 153.21 & 150.38 & 149.56 & 118.22 & 120.27 & 118.43 & 117.74 \\
\hline Fecundity & & 71.74 & 62.34 & 69.64 & 79.92 & 120.10 & 107.30 & 114.70 & 122.30 \\
\hline
\end{tabular}

M: Mango; Cn: Cinnamon; Ca: Cashew; S: Som

6.55-8.06 days (on A. occidentale) to 6.70-8.85 days (on M. bombycina). The developmental period was shortest on all the host plants in May-October generation. The second instar development was shortest on A. occidentale (4.83-5.95 days) and M. bombycina (4.83-6.13 days) and longest on M. indica (4.93-6.10 days) and C. cassia (4.98-5.95 days). The developmental duration for second instars was longest in January-March generation and shortest in March-May generation. The developmental time of the third instar larvae ranged from 5.20-5.45 days in October-January generation to
7.00-7.18 days in that of January-March. It was significantly shortest 5.20-7.08 days on A. occidentale and longest 5.20-7.18 days on $M$. indica. The developmental time of fourth instar larvae was significantly shortest on $M$. indica (5.48-6.38 days) and longest on M. bombycina (6.05-6.58 days). The fifth instar larvae took shortest time to complete development in October-January generation and significantly longest in March-May generation on all the host plants. The period was longest on C. cassia (6.55-7.95 days) and shortest on $A$. occidentale (6.23-6.90 days). The last instar larval 


\begin{tabular}{|c|c|c|c|c|c|c|c|c|c|c|}
\hline \multirow{2}{*}{$\begin{array}{l}\text { Variance } \\
\text { source }\end{array}$} & & \multirow{2}{*}{$\begin{array}{c}\text { Incuba- } \\
\text { tion }\end{array}$} & \multicolumn{6}{|c|}{ Larva } & \multicolumn{2}{|c|}{ Pupa } \\
\hline & & & $1^{\text {st }}$ & $2^{\text {nd }}$ & $3^{\text {rd }}$ & $4^{\text {th }}$ & $5^{\text {th }}$ & $6^{\text {th }}$ & Male & Female \\
\hline \multirow{3}{*}{$\begin{array}{l}\text { Generation } \\
d f=3\end{array}$} & MS & 96.057 & 15.012 & 5.092 & 11.759 & 0.965 & 6.555 & 6.821 & 19125.107 & 21277.641 \\
\hline & $\mathrm{F}$ & 2465.43 & 2946.43 & 2512.23 & 4254.81 & 415.00 & 3119.44 & 3014.85 & 2932.72 & 4850.50 \\
\hline & $\mathrm{Pr}>\mathrm{F}$ & $<0.000$ & $<0.000$ & $<0.000$ & $<0.000$ & $<0.000$ & $<0.000$ & $<0.000$ & $<0.000$ & $<0.000$ \\
\hline \multirow{3}{*}{$\begin{array}{l}\text { Host } \\
d f=3\end{array}$} & MS & 0.049 & 0.517 & 0.037 & 0.013 & 0.513 & 2.026 & 4.238 & 13.431 & 15.390 \\
\hline & $\mathrm{F}$ & 26.23 & 2.26 & 2.01 & 2.89 & 165.25 & 964.32 & 1285.26 & 278.81 & 1032.39 \\
\hline & $\mathrm{Pr}>\mathrm{F}$ & 0.0017 & 0.0445 & 0.0251 & 0.0452 & 0.0009 & 0.0000 & $<0.000$ & 0.0000 & 0.0000 \\
\hline \multirow{3}{*}{$\begin{array}{l}\text { Generation } \\
x \text { Host } \\
d f=9\end{array}$} & MS & 0.030 & 0.236 & 0.033 & 0.046 & 0.236 & 0.284 & 0.667 & 1.628 & 1.308 \\
\hline & $\mathrm{F}$ & 1.104 & 1.89 & 2.31 & 2.02 & 10.42 & 135.19 & 165.67 & 33.79 & 80.23 \\
\hline & $\mathrm{Pr}>\mathrm{F}$ & 0.5265 & 0.0325 & 0.0304 & 0.0410 & 0.0107 & 0.0032 & $<0.000$ & 0.0151 & 0.0089 \\
\hline \multicolumn{11}{|c|}{ Table 2: Continue... } \\
\hline \multirow{2}{*}{$\begin{array}{l}\text { Variance } \\
\text { source }\end{array}$} & & & \multicolumn{2}{|c|}{ Adult longevity } & \multicolumn{4}{|c|}{ Total development } & \multirow{2}{*}{\multicolumn{2}{|c|}{ Fecundity }} \\
\hline & & & Male & Female & & Male & Fer & nale & & \\
\hline \multirow{3}{*}{$\begin{array}{l}\text { Generation } \\
d f=3\end{array}$} & MS & & 0.510 & 1.453 & & 7841.164 & 996 & 5.821 & 9988. & 083 \\
\hline & $\mathrm{F}$ & & 526.69 & 886.31 & & 5210.38 & 695 & 1.61 & 1400 & 62 \\
\hline & $\mathrm{Pr}>\mathrm{F}$ & & 0.0000 & $<0.000$ & & 0.0000 & & 000 & $<0.0$ & \\
\hline \multirow{3}{*}{$\begin{array}{l}\text { Host } \\
d f=3\end{array}$} & MS & & 0.229 & 0.051 & & 47.328 & 384 & 256 & 489 & \\
\hline & $\mathrm{F}$ & & 236.27 & 31.10 & & 521.30 & & 2.64 & 68. & \\
\hline & $\mathrm{Pr}>\mathrm{F}$ & & 0.0111 & 0.0285 & & 0.0000 & & 001 & $<0.0$ & \\
\hline \multirow{3}{*}{$\begin{array}{l}\text { Generation } \\
x \text { Host } \\
d f=9\end{array}$} & MS & & 0.083 & 0.051 & & 3.553 & & 344 & 32.9 & \\
\hline & $\mathrm{F}$ & & 85.40 & 20.65 & & 89.65 & & .76 & 4.6 & \\
\hline & $\operatorname{Pr}>\mathrm{F}$ & & 0.0465 & 0.0475 & & 0.0001 & & 002 & $<0.0$ & \\
\hline
\end{tabular}

$\mathrm{Pr}>\mathrm{F}=0.0500$ significance

development was also longest on C. cassia (8.85-10.50 days) and shorter on M. bombycina (8.13-9.30 days). The sixth instar larvae took shortest period to undergo pupation in JanuaryMarch generation and longest in March-May (Table 1 and 2).

\subsection{Pupal period}

The pupal developmental period was longest in May-October (88.20-95.30 days) generation and significantly shortest in January-March (22.00-24.40 days) one. On the same host plant, male pupae took shorter time to complete development to adult than females on all host plant. The period was significantly longest on $C$. cassia and shortest on $M$. bombycina (Table 1 and 2).

\subsection{Longevity and fecundity}

Results of the statistical analysis showed a significant difference between different generations and host plants on which the adults developed in terms of longevity. The shortest female longevity was 3.37 days on M. bombycina in May-October generation, while the longest longevity was observed in the October-January generation on A. occidentale (4.15 days). Male longevity showed the same pattern as that of females, with the longest longevity of 3.51 days on C. cassia in the October-January generation. The male longevity was shortest 2.79 days on A. occidentale in the January-March generation. On the same host plant male longevity was found to be shorter than that of females throughout the generations (Table 2 and 3 ).

The difference between the fecundity of different generations developed on different host plants was statistically significant (Table 2). The highest fecundity was found in the OctoberJanuary generation. There was no significant difference in the number of eggs laid by $C$. trifenestrata of March-May and May-October generation. The females reared on $M$. bombycina laid the highest number of eggs (71.83-122.30) compared to females developed on other host plants. The egg production was significantly lowest in females reared on 
C. cassia (62.34-107.30).

\subsection{Overall development from egg to adult}

The generation time was shorter on $M$. bombycina (85.57-145.12 days and 86.35-149.56 days for males and females, respectively) and $M$. indica (84.97-143.63 days and 87.27-148.55 days for males and females, respectively), whereas it was longest on C. cassia (88.56-147.93 days and 90.28-153.21 days for males and females, respectively). The overall developmental duration was shortest in March-May generation and longest in May-October generation.

3.6. Development threshold and thermal constant for $C$. trifenestrata

Information on temperature-dependent duration was used to determine the threshold of development and threshold constant for different $C$. trifenestrata developmental stages. The regression equations were established between temperatures and respective developmental rate which was reciprocal of duration of development of stages recorded in different host plants in a generation. Developmental threshold were determined to be 15.85-28.26, 19.28-26.63, 22.1631.71 and $20.36-32.56^{\circ} \mathrm{C}$ for egg, larva, pupa, and adult in all the four generations respectively with corresponding thermal constant being 92.00-147.28, 236.97-833.33, 100.81-977.52 and 21.75-62.81 degree days (DD). The thermal requirements for complete development were calculated as 1016.10 DD at $20.13^{\circ} \mathrm{C}$ and $65.79 \% \mathrm{RH}$ for the first generation, 943.74 DD at $25.87^{\circ} \mathrm{C}$ and $72.50 \% \mathrm{RH}$ for the second generation, 1971.08 $\mathrm{DD}$ at $27.98{ }^{\circ} \mathrm{C}$ and $83.97 \% \mathrm{RH}$ for the third generation, $1224.80 \mathrm{DD}$ at $20.99{ }^{\circ} \mathrm{C}$ and $79.13 \% \mathrm{RH}$ for the fourth generation (Table 3).

Results of this study showed that $C$. trifenestrata developed in the four (4) host plants tested but the biological parameters measured varied significantly across the host plants in different generations completed in a year. In case of insect

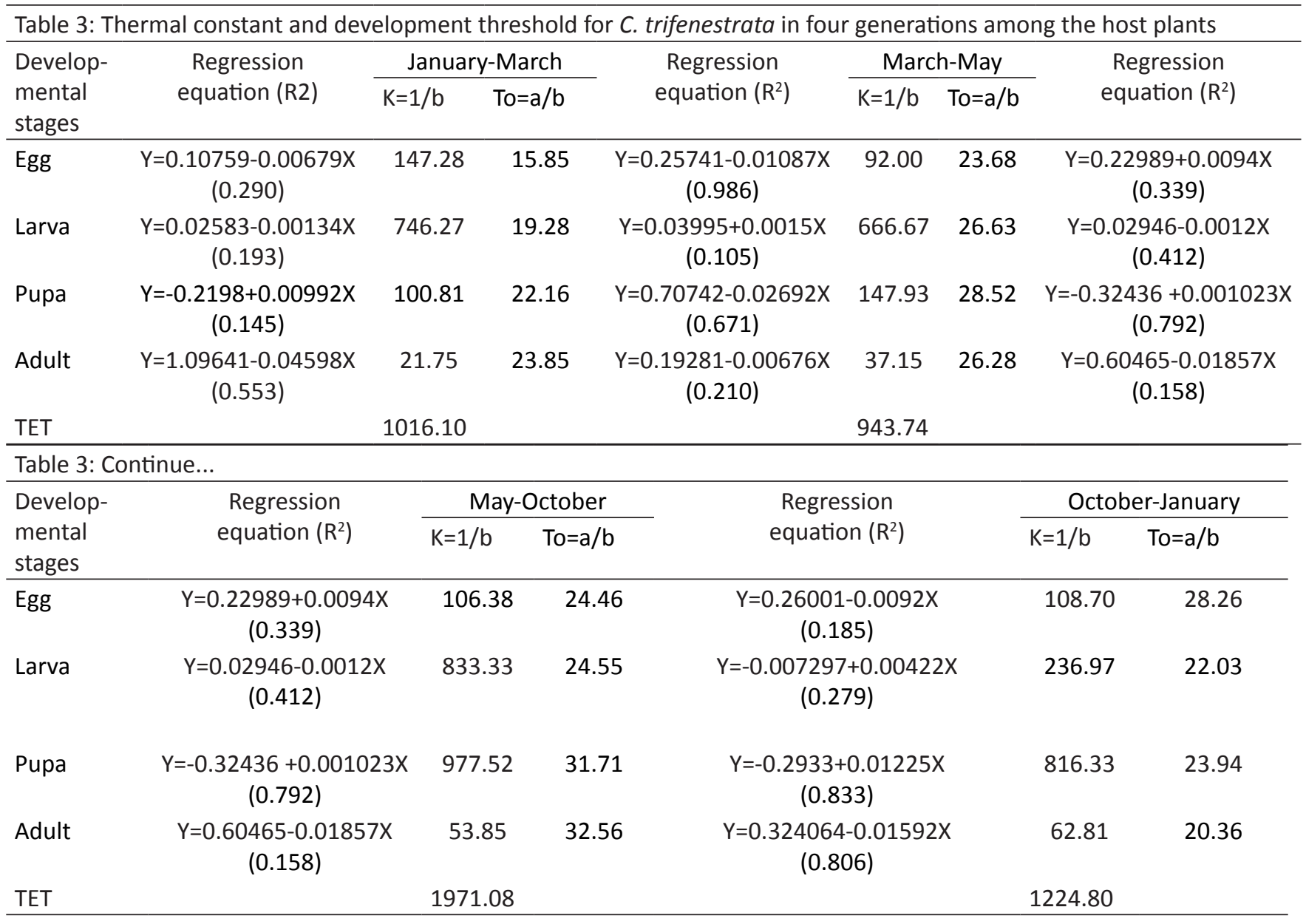

K: Thermal constant; To: Development threshold; TET: Total effective temperature (DD)

pest management there present a significant linkage between population fluctuation, various physiological process and different environmental temperatures. In understanding the host suitability under different environmental condition study of the effect of host plants on the biology of insects is important (Xue, 2009). The developmental response of insects to temperature is important to understand the ecology of insect life histories. 
Previous studies have suggested that $C$. trifenestrata completes four generations in a year (Huq et al., 1991; Bera, 2013; Tikader et al., 2014). Earlier workers recorded the incubation period of $10.40 \pm 0.55$ days on Cardamom (Yadav and Kumar, 2003); 9-11 days on Mango (Huq et al., 1991; Amin et al., 2008 and Wibowo et al., 2004); 10.30 days to 15.80 days on Mango (Bera, 2013); 10-12 days in summer and 15-20 days in winter on Som (Tikader et al., 2014). Our results concur with these findings. Contrary to our study, earlier reports made by Huq et al., 1991; Hossain et al., 2004; Yadav and Kumar, 2003, Ahmed and Alam, 1994; Amin et al., 2008 and Tikader et al., 2014 suggested five larval instars of C. trifenestrata. The reason in variation of number of instar needs elaborate investigation. Nevertheless, irrespective of developmental stage, larvae fed on M. bombycina took less time to complete their development. M. bombycina was undoubtedly the superior host for last instar larvae as inferior host quality typically leads to prolonged development (Awmack and Leather, 2002; Coley et al., 2006). The duration of first three instars $\left(1^{\text {st }}\right.$ to $\left.3^{\text {rd }}\right)$ was reported; 5.4 and 5.2 days of $1^{\text {st }}$ instar; 5.7 and 5.3 days of $2^{\text {nd }} ; 6.1$ and 6.0 days of $3^{\text {rd }}$ instar stages for I and II generations (Ahmed and Alam, 1994), 5.15, 5.10, 5.30 days (Hossain et al., 2004), 5.3 \pm 0.3 , $5.1 \pm 0.31,6.1 \pm 0.35$ days (Amin et al., 2008) and 3-4 to 6-8 days, $3-5$ days; $5-7$ to $7-10$ days (Tikader et al., 2014). This is confirmed by the current study. The developmental period of last three larval stages on $M$. indica $\left(4^{\text {th }}\right.$ to $6^{\text {th }}$ ) obtained in the present study differed with the work done by Ahmed and Alam (1994) (5.00-6.50 days) and Huq et al. (1991) (5.80-6.20 days). Our results illustrate that the duration of $6^{\text {th }}$ stage larvae of the March-May generation was 8.80-10.50 days that is at par with that of $5^{\text {th }}$ stage larvae (10-12 days) as reported by Tikader et al. (2014). Tikader (2012) found five (5) months of pupal diapause confirmed the present study. The duration of pupal stages as added by the earlier reports supported the present result for different generations; 26 days for MarchMay generation (Ali and Karim, 1991); 68.16 \pm 2.13 days for October-January generation (Yadav and Kumar, 2003); 24.40-93.20 days in all the generations (Bera, 2013). But the converse was true for Tikader et al. (2014). Amin et al. (2008) and Hossain (1989) also recorded adult longevity of 2 to 5 days on Mango. The fecundity of a female as recorded by various workers suggested that it varied from 150-250 (Huq et al., 1991; Yadav and Kumar, 2003; Hossain et al., 2004; Amin et al., 2008; Tikader et al., 2014). In our research, fecundity of $C$. trifenestrata was generally found to be shorter than in other studies. We believe that this result is due to daily changes in parameters such as temperature and humidity.

It is believed that there is relation between decreases in the number of eggs to increased temperature. It was observed that in addition to increasing the speed of growth, rearing of $C$. trifenestrata on the host plant ( $M$. indica and $M$. bombycina) resulted in higher progeny production and adult longevity. Van Lenteren and Noldus (1990) stated that the suitability of the plant depends on shorter pre-reproductive period and increased reproductive capacity of an insect on a host. This is confirmed by the current study and although we did not measure the nutritional content of the tested plant species, it is probable that it might have played a role in enhancing the reproductive success of $C$. trifenestrata on the suitable host plants. Although $C$. trifenestrata was observed to lay eggs on C. cassia, egg production was generally low when compared with reproduction on the other host plants. Leather (1995) noted that when an insect pest encounters a poor-quality host plant, it may modify its oviposition behavior, by reducing the number of eggs laid on each plant. Cricula trifenestrata development on plants such as $M$. indica and $M$. bombycina may result in rapid development and greater numbers of $C$. trifenestrata surviving to adulthood, and hence more damage on these host plants mainly during January to May; and this observation has significant implications for management of the pest on these host plants.

Thermal constant provides better prediction of insect development than developmental period. Depending upon ambient temperature and development threshold, heat units are accumulated until fulfillment of thermal constant requirement, which heralds completion of development of insect life cycle or a development stage (Polat et al., 2016).

\section{Conclusion}

In summary, $C$. trifenestrata completed four generations on different host plants in a year in terai of West Bengal, India and the generation time changed according to temperature and relative humidity. Biological properties of the pest changed in each generation. The insect developed very fast during January to May particularly on $M$. indica and $M$. bombycina. Females from $M$. indica and $M$. bombycina laid most of their eggs in October-January generation. The thermal requirement for complete development was also highest for May-October generation and lowest for March-May generation.

\section{Future Research}

The thermal constant provides a valuable tool for insect pest control; in forecasting infestations monitoring, to predict the appearance of insect stages and timing of insecticide application in order to control them in a timely manner, ensuring its rational management. The validation of this temperature threshold and thermal constant is the next step to develop a forecasting model for predicting the occurrence of $C$. trifenestrata under field conditions. Determination of biological properties is crucial for the correct timing of pest control applications. This knowledge may also enable to take important step towards developing successful Integrated Pest Management strategies of this polyphagous pest.

\section{References}

Ahmad, F., Alam, M.Z., 1994. Biology of mango defoliator 
C. trifenestrata Helfer (Lepidoptera:Saturniidae). Bangladesh Journal of Scientific Research 12(2), 151-156.

Ahmad, M., Ahmad, M., 1991. A new host plant record for the mango defoliator, $C$. trifenestrata, from Mymensingh, Bangladesh. Department of Entomology, Bangladesh Agricultural University, Mymensingh- 2202. Bangladesh Journal of Entomology 1, 89.

Ahmed, S.A., Dutta, L.C., Sarmah, M.C., 2012. Bio-Efficacy of some Insecticides against Leaf Eating Caterpillar, Cricula trifenestrata Helfer (Lepidoptera: Saturniidae) Infesting Som, Persea bombycina Kost. Plantation Academic Journal of Entomology 5(2), 94-98.

Ali, M.I., Karim, M.A., 1991. Notes on the biology, behaviour and biocontrol agents of Mango defoliator, Cricula trifenestrata (Lepidoptera: Saturniidae) in Bangladesh. Bangladesh Journal of Entomology 1(1), 83-87.

Amin, M.R., Ahad, M.A., Rono, M.M.A., Tithi, D.A., 2008. Life history traits of Cricula trifenestrata (Lepidoptera: Saturniidae) feeding on Mangifera indica. Journal of Agroforestry and Environment 2(1), 1-6.

Arora, G.S., Gupta, I.J., 1979. Taxonomic studies of the some of the Indian vanya silk moths (Lepidoptera: Saturniidae: Saturniinae). Memoirs of the Zoological Survey of India 16, 1-63.

Awmack, C.S., Leather, R.S., 2002. Host plant quality and fecundity in herbivorous insects. Annual Review of Entomology 47, 817-844.

Benrays, E.A., Chapman, R.F., 1994. Host plant selection by phytophagous insects. Chapman \& Hall, New York, USA, 312.

Bera, C., 2013. Studies on morphology and biology of Mango defoliator, Cricula trifenestrata Helf. in terai region of West Bengal. M.Sc. Thesis. Uttar Banga Krishi Viswavidyalaya, Pundibari, Cooch Behar.

Biswas, S., Hath, T.K., Ray, N., 2013. Effect of different host plants on nutritional indices of wild silk moth, Cricula trifenestrata. Journal of Entomological Research 37(3), 223-227.

Chaudhuri, N., Ghosh, J., 2012. Food utilization efficiencies of mango defoliator Cricula sp. in terai region of West Bengal. Journal of Mycology and Plant Pathology 42(4), 545.

Coley, P.D., Bateman, L.M, Kursar, T.A., 2006. The effects of plant quality on caterpillar growth and defense against natural enemies. Oikos 115, 219-228.

Das, D.K., Dutta S.K., Khanikor, D.P., 1999. Incidence of insect pests on som in Jorhat and Goalpara districts of Assam. Department of Entomology, Assam Agricultural University, Jorhat 785013, Assam, India. Journal of the Agricultural science society of North East India 12(1), 75-78.

Ghosh, C.C., 1940. The mango hairy caterpillar (Cricula trifenestrata Helfer). Insect pest of Burma. Government printing and stationary Rangoon, 161-162.

Ghosh, J., Chaudhuri, N., Bera, C., 2015. Bio-Ecological analysis to identify the critical stage of development of mango defoliator Cricula trifenestrata (Lepidoptera: Saturniidae). International Journal of Recent Scientific Research 6(11), 7259-7262.

Hossain, A.K.M.A., 1989. A field guide on insect pest and diseases of Mango in Bangladesh and their control. Division of Horticulture, BARI and FAO/UNDP Mango Improvement and Development 14.

Hossain, M.A.E.I., Taj, F.H., Ahad, M.A., Ara, R., 2004. Biology and food consumption of Mango defoliator Cricula trifenestrata (Stauriniidae:Lepidoptera). Journal of Agriculutre Education and Technology 7(1\&2), 83-88.

Huq, S.B., Hossain, M., Khan, A.B., 1991. Biology of Cricula trifenestrata (Lepidoptera: Saturniidae), a leaf eating caterpillar of Mango. Bangladesh Journal of Entomology 1, 19-26.

Khaliq, A., Javed, M., Sohail, M., Sagheer, M., 2014. Environmental effects on insects and their population Dynamics. Journal of Entomology and Zoology Studies 2(2), 1-7.

Kipyatkov, V.E., Lopatina, E.B., 2010. Intra-specific variation of thermal reaction norms for development in insects: new approaches and prospects. Entomological Review 90, 163-184.

Lampe, R.E.J., 2010. Saturniidae of the world. Pfauenspinner der Welt: their life stages from the eggs to the adults... ihre Entwicklungsstadien vom Ei zum Falter. Verlag Dr. Friedrich Pfeil, München, 368.

Leather, S.R., 1995. The effect of temperature on oviposition, fecundity and egg hatch in the pine beauty moth, Panolis flammea (Lepidoptera: Noctuidae). Bulletin of Entomological Research 84, 515-520.

Mandal, R.C., 2000. Pests of cashew. Cashew production and processing technology. Agrobios, Jodhpur, 123.

Miller, J.R., Miller, T.A., Berenbaum, M., 1986. Insectplant interactions. Springer-Verlag, Dordrecht, The Netherlands.

Nair, M.R.G.K., 1975. Insects and mites of crops. Indian Council of Agricultural Research, New Delhi, 193.

Pal, S., Medda, P.S., 2006. Occurrence of wild silk moth, Cricula trifenestrata Helfer on cashew (Anacardium occidentale L.) under Terai conditions of West Bengal. The Orissa Journal of Horticulture 34, 117.

Polat, B., Ali O., Ali K.S., 2016. Studies of selected biological parameters of tomato leafminer Tuta absoluta (Meyrick), (Lepidoptera: Gelechiidae) under natural conditions. Phytoparasitica 44, 195-202.

Rajesh, G., Zacharia, G., 2011. Silk from cashew pest can boost income, In: abstract of Frist International Symposium on Cashew nut-2011, Madurai, December 9-12.

Tikader, A., 2012. A new record of Brachymeria tibialis (Walker) (Hymenoptera: Chalcididae) on Cricula 
trifenestrata (Helfer) from India. Munis Journal of Entomology and Zoology 7, 222-225.

Tikader, A., 2011. Cricula trifenestrata Helfer feed on different plants, -A new report. Geobios 38, 151-155.

Tikader, A., Vijayan, K., Saratchandra, B., 2014. Cricula trifenestrata Helfer (lepidoptera: Saturniidae) - a silk producing wild insect in India. Tropical Lepidoptran Research 24(1), 22-29.

Van Lenteren, J.C., Noldus, L.P.J.J., 1990. Whitefly-plant relationships: behavioural and ecological aspects, pp. 47-90 In D. Gerling [ed.], Whiteflies: Their Bionomics, Pest Status and Management. Intercept Ltd, Andover, Hants, UK.
Wibowo, I.H., Okid, P.A., Budiharjo, S., 2004. Effect of temperature and photoperiod on the Old Stadia Silkworm Egg Gold (Cricula trifenestrata helf.). Biosmart 6(1), 71-74.

Xue, M., Pang, Y.H., Wang, H.T., Li, Q.L., Liu, T.X., 2009. Effects of four host plants on biology and food utilization of the cutworm. Spodoptera litura. Journal of Insect Science 10, 1-14.

Yadav, S., Kumar, A., 2003. New record of wild silk caterpillar Cricula trifenestrata Helfer on large cardamon and notes on it's biology. Uttar Pradesh Journal of Zoology 23(1), 67-69. 